\title{
Optimisation of sludge disruption by sonication
}

\author{
Kuan-Yeow Show ${ }^{a, *}$, Taohong Mao ${ }^{b}$, Duu-Jong Lee ${ }^{c}$ \\ ${ }^{a}$ University of Tunku Abdul Rahman, 13 Jalan 13/6, 46200 Petaling Jaya, Selangor, Malaysia \\ ${ }^{\mathrm{b}}$ School of Civil \& Environmental Engineering, Nanyang Technological University, Singapore 639798, Singapore \\ ${ }^{\mathrm{c} D e p a r t m e n t}$ of Chemical Engineering, National Taiwan University, Taipei 10617, Taiwan
}

\section{A R T I C L E I N F O}

Article history:

Received 28 March 2007

Received in revised form

9 July 2007

Accepted 15 July 2007

Available online 21 July 2007

Keywords:

Sonication

Ultrasound

Cavitation bubbles

Disruption

Sludge disruption

Solids content

\begin{abstract}
A B S T R A C T
This study presents an examination on the correlation of sonication operating condition, sludge property, formation and behaviour of cavitation bubbles in sludge disruption under low-frequency ultrasound sonication. The influence of sonication time, sonication density, type of sludge and solids content on the disruption was evaluated. The most vigorous particle disruption was achieved in the initial period of sonication, which subsided subsequently. The explosive effect was likely due to the rapid cavitation arising from powerful transient bubbles generated in fractions of microseconds. A rating for the type of sludge was derived based on the finding that particles in secondary sludge were more readily disrupted than both primary sludge and mixed sludge. While sonication density exhibited the most significant role in cavitation bubble formation and behaviour, particle disruption could be optimised for energy input by sonicating at higher sonication density and shorter sonication time. Based on theoretical consideration, it was deduced that within an optimum sludge solids content ranging between $2.3 \%$ and $3.2 \%$, superior particle disruption could be accomplished within a minute for secondary sludge sonicated at a density of $0.52 \mathrm{~W} / \mathrm{mL}$. Useful guidelines for sonication system installation, equipment protection and process reliability could be established from knowledge derived from a good understanding on the influence of solids content on sludge sonication.
\end{abstract}

(c) 2007 Elsevier Ltd. All rights reserved.

\section{Introduction}

Anaerobic digestion is commonly applied for stabilisation of sewage sludge. Large digesters are normally designed to accommodate the rate-limiting hydrolysis stage in the entire anaerobic biochemical reactions. Digestion could be enhanced by including a pretreatment process to accelerate the hydrolysis reactions prior to anaerobic digestion (Eastman and Ferguson, 1981). Compared with other methods, ultrasonication has been considered an environmentally and economically sound pretreatment (Tiehm et al., 1997). Highpower ultrasound at low frequencies could generate intensive cavitation, which results in vigorous and effective sludge disruption leading to substantial release of intra-cellular materials into the bulk liquid (Neis et al., 2000). In addition, some insoluble particulate organic matter may even be transformed into a soluble state under the cavitational explosion of transient bubbles (Jorand et al., 1995; Chiu et al., 1997; Mao et al., 2004). The disruption of sludge particles derived from sonication treatment would enhance subsequent acidogenesis, acetogenesis and methanogenesis reactions, which would in turn lead to an improvement in methane generation and reduction of sludge volume (Onyeche et al., 2002; Mao and Show, 2007).

A comprehensive understanding of the influence of sonication on anaerobic digestion of sludge requires inter-disciplinary knowledge in sonication mechanisms and anaerobic biochemical reactions. While literature on anaerobic digestion of

*Corresponding author. Tel.: +603 7958 2628; fax: +60379561923.

E-mail address: kyshow@gmail.com (K.-Y. Show).

0043-1354/\$ - see front matter @ 2007 Elsevier Ltd. All rights reserved.

doi:10.1016/j.watres.2007.07.017 
sludge has been extensively documented, the mechanism of particle disruption in sludge sonication is yet to be derived. Although it is believed that ultrasonic sludge disruption is mainly attributed to the phenomenon of cavitation bubbles during sonication (Harrison, 1991; Tiehm et al., 1997), the correlation among cavitation bubbles, sonication parameters and sludge disruption is yet to be understood and established.

As sonication is an energy-intensive process, the costeffectiveness of this technique may raise concerns on the wastewater treatment industry. Consideration on process optimisation has barely been examined in existing literature on sludge sonication, perhaps due to a lack of overall investigation of the operating conditions. Lack of a good understanding on the complex correlations among the diverse sludge characteristics, sonication density and duration renders this technique a difficult optimisation on the energy cost and effective disruption.

In an attempt to establish cost-effective sludge sonication, this study explored the influence of operating conditions in terms of sonication time, sonication density, type of sludge and solids content based on a specific energy evaluation. The role and significance of cavitation bubble formation, collapse and behaviour in sludge sonication are discussed. An emphasis of the study is to incorporate cavitation kinetics into the discussion on sonication mechanisms.

\section{Materials and method}

\subsection{Sonication treatment}

Sludge samples were collected from a water reclamation plant in Singapore treating municipal wastewater. The primary sludge, consisting predominantly of readily settleable solids of raw wastewater, was collected from the primary clarifier. The secondary sludge was obtained from a sampling point after activated sludge treatment and thickening.

Sonication was conducted with an ultrasound reactor equipped with a probe transducer (Autotune Series, Sigma Chemical Co., USA). The frequency was $20 \mathrm{kHz}$ and the maximum power output was $200 \mathrm{~W}$. Fifty millilitres of sludge sample was placed in a beaker with the probe placed at the middle of the sample, which was at a level of about $2 \mathrm{~cm}$ above the beaker bottom. Sludge samples were sonicated at different sonication times ranging from 0.5 to $15 \mathrm{~min}$ and at sonication densities between 0.18 and $0.52 \mathrm{~W} / \mathrm{mL}$. Table 1 lists the sonication conditions applied on the samples. Sludge

\section{Table 1 - Sonication conditions}

\begin{tabular}{lccc}
\hline Sample & $\begin{array}{c}\text { Sonication } \\
\text { intensity (W/ } \\
\mathrm{cm}^{2} \text { ) }\end{array}$ & $\begin{array}{c}\text { Sonication } \\
\text { density (W/ } \\
\text { mL) }\end{array}$ & $\begin{array}{c}\text { Energy } \\
\text { input } \\
\text { (W) }\end{array}$ \\
\hline 1 & 0 & 0 & 0 \\
2 & 32 & 0.18 & 90 \\
3 & 56 & 0.33 & 166 \\
4 & 92 & 0.52 & 260 \\
\hline
\end{tabular}

samples with different solids contents ranging from $0.98 \%$ to $3.75 \%$ total solids (TS) were also evaluated.

Sludge particle size analysis was determined using a Malvern Laser Diffraction Particle Size Analyzer (model 2601Lc, Malven Instruments Ltd., Malvern, UK). Soluble chemical oxygen demand (SCOD) and total chemical oxygen demand (TCOD) were measured in accordance with the procedures specified in Standard Methods (APHA, 1998).

\section{Results and discussion}

\subsection{Sonication time}

The extent of sludge disruption due to sonication time can be quantified in terms of particle size reduction and release of SCOD. Cavitation bubbles were generated continuously from the probe transducer once the power was turned on. As soon as the transducer was turned off, bubble generation ceased and the liquid agitation stopped immediately. As shown in Fig. 1, particle disruption was apparently related to the exposure time in the ultrasonic field. Drastic particle size reduction along with a distinct release of inter-cellular substances measured as SCOD was noted in the initial $1 \mathrm{~min}$ of sonication, and the disruption subsided subsequently. The results suggested that sonication could be set for less than a minute for energy cost optimisation.

To better understand the extent of sonication time on particle disruption, the particle size distributions were analysed with respect to sonication time. Fig. 2 illustrates that particles larger than $4.4 \mu \mathrm{m}$ (including $4.4<d \leqslant 50 \mu \mathrm{m}$, $50<d \leqslant 125 \mu \mathrm{m}$ and $d \geqslant 125 \mu \mathrm{m}$ ) exhibited the most intense disruption in the initial $1 \mathrm{~min}$, and the disruption became marginal on further sonication. It appeared that micro-flocs $(<4.4 \mu \mathrm{m})$ were less susceptible to ultrasonic disruption than macro-flocs $(>4.4 \mu \mathrm{m})$. It could be interpreted that the binding forces in micro-flocs, such as cells, are much stronger than those in macro-flocs that are made up of a more loosely bound aggregation. It is also likely that macro-flocs have larger surface areas exposed to the sonication, causing a greater extent of disruption.

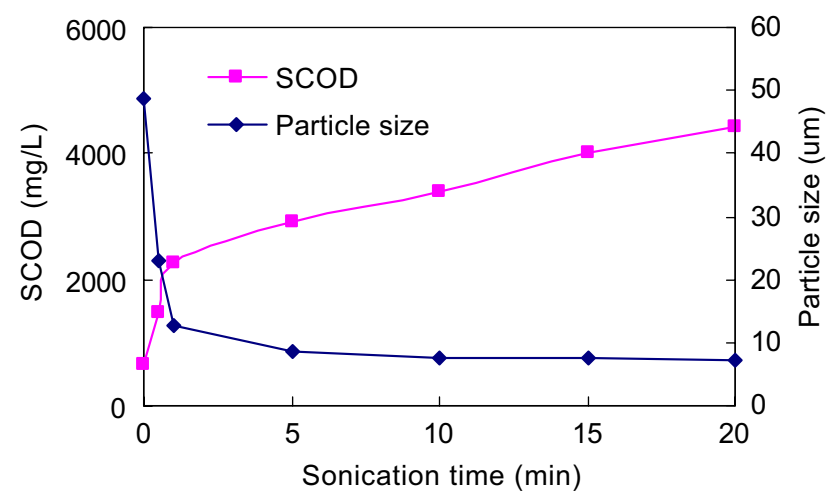

Fig. 1 - Effects of sonication time on SCOD and particle size (sonication density was fixed at $0.52 \mathrm{~W} / \mathrm{mL}$ ). 


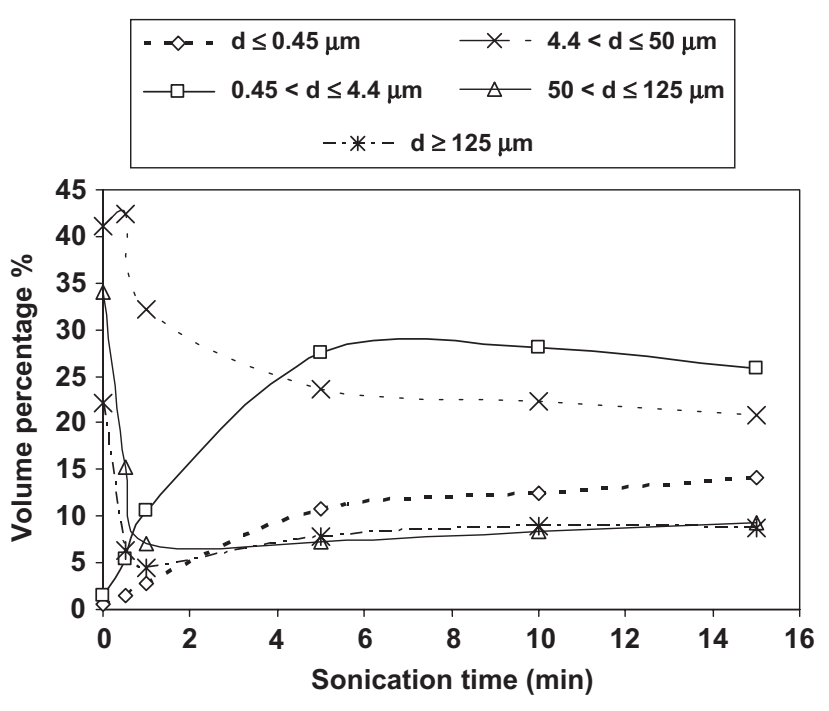

Fig. 2 - Effect of sonication time on particle size distribution (sonication density was fixed at $0.52 \mathrm{~W} / \mathrm{mL}$ ).

\subsubsection{Discussion on sonication time}

Sludge disruption is accomplished due to the cavitational effects caused by sonication waves. Cavitation lies in the formation of tiny discontinuities or cavities in liquids, followed by their growth, pulsation and collapse. If the bubble formation requirements are satisfied, the initial cavity/nuclei will grow in size. The time of bubble growth proposed by Abramov (1998) is represented by

$\tau_{\mathrm{g}}=0.75 \mathrm{~T}+(\mathrm{i}-1) \mathrm{T}$,

$\mathrm{T}=\frac{1}{f}$,

where $\tau_{\mathrm{g}}$ is the time of bubble growth, $f$ is the ultrasound frequency, $T$ is the period of ultrasound wave and $i$ is the number of acoustic cycles the bubble experienced.

Once the bubble begins to grow, subsequent behaviour of the bubble is diverse. Two distinct bubble behaviours are normally identified, namely stable bubbles and transient bubbles. Stable bubbles are generated under conditions where the peak sound pressure in the rarefaction cycle is not strong enough to force the bubble to expand its collapse radius. Stable bubbles normally oscillate for a time scale of thousands of acoustic cycles as expressed in Eq. (1) (Laborde et al., 1998). Taking the case of 5000 acoustic cycles and the sound frequency of $20 \mathrm{kHz}$ applied in the present study, the time for one stable bubble to exist was calculated as follows:

$\tau_{\mathrm{g}}=0.75 \mathrm{~T}+(\mathrm{i}-1) \mathrm{T} \approx 0.25 \mathrm{~s}$.

On the other hand, transient cavitation refers to the fact that acoustic pressure is able to exert cavity expansion to its resonant radius in half or several acoustic cycles and then collapse rapidly. Taking the case of 10 acoustic cycles, the time for a transient bubble to grow was calculated as $0.0005 \mathrm{~s}$.

Based on the formula developed by Abramov (1998), the duration of collapse can be expressed as

$\tau_{\mathrm{C}}=0.915 R_{\max } \sqrt{\frac{\rho_{\mathrm{L}}}{\mathrm{P}_{0}}}$ where $\tau_{c}$ is the collapse time, $R_{\max }$ is the resonant or maximum radius $(\mathrm{cm}), \rho_{\mathrm{L}}$ is the density of liquid and $P_{0}$ is the pressure of the system. The resonant radius $R_{\max }$ is inversely proportional to the ultrasound frequency and can be approximated by Eq. (4), where the unit of $R_{\max }$ is expressed in $\mathrm{mm}$ (Young, 1980):

$R_{\max } \approx 3.28 \frac{1}{f}$.

Assuming $\rho_{\mathrm{L}}$ as $1000 \mathrm{~kg} / \mathrm{m}^{3}$ and $P_{0}$ as atmospheric pressure $10^{5} \mathrm{~Pa}$ at a sludge liquid height of $10 \mathrm{~cm}$, the time for transient bubble collapse in the present study can be calculated as

$\tau_{\mathrm{c}}=0.915 \mathrm{R}_{\max } \sqrt{\frac{\rho_{\mathrm{L}}}{\mathrm{P}_{0}}} \approx 0.0015 \mathrm{~s}$.

Hence, the total period for the existence of transient bubble is the sum of its growing and collapse times, which sums up to about $0.002 \mathrm{~s}$. Compared with a time scale of $0.25 \mathrm{~s}$ for a stable bubble, the existence of transient bubbles is much shorter.

Studies have shown that it is at the moment of bubble implosion that non-linear energy transformation occurs within a very small volume that would trigger localised extreme temperatures $(5000 \mathrm{~K})$ and high pressure (tens of thousands of MPa) (Laborde et al., 1998; Neis et al., 2000). Hence, transient bubbles should be regarded as the major contributor for sludge disruption. Although stable bubbles could pulsate and move around the bulk liquid, which may also contribute to floc dispersion, its disruption is not comparable to that of transient bubbles. More violent than stable bubbles, transient bubbles are able to bring about nonlinear phenomena in liquid.

The theoretical consideration presents evidence that sludge particle disruption was most profound in the initial period of sonication. As the evolution of powerful implosion of transient bubbles is extremely fast, particles could be disrupted within fractions of a second. As compared with other sludge treatment methods, the postulated physical mechanism relating to cavitation bubbles also highlights the efficacy of sludge sonication. The treatment times for some methods such as alkali or ozone treatment normally amount to several hours, and in some cases even more than $24 \mathrm{~h}$ before the effect can be seen (Weemaes et al., 2000).

\subsection{Sonication density}

The relationship of specific energy expressed as power requirement $(\mathrm{kWh})$ per $\mathrm{kg}$ of dried solids sonicated (DS) with the mean particle size at different sonication density is depicted in Fig. 3(a). Interestingly, sonication at higher density was found to be more energy cost-effective on sludge disruption. For example, at the same specific energy of $10 \mathrm{kWh} / \mathrm{kgDS}$, the treatment can reduce the particle size from 49 to $9 \mu \mathrm{m}$ at a density of $0.52 \mathrm{~W} / \mathrm{mL}$, but the reduced particle sizes were larger at 13 and $19 \mu \mathrm{m}$ sonicated at 0.33 and $0.18 \mathrm{~W} / \mathrm{mL}$, respectively. As shown in Fig. $3(\mathrm{~b})$, the SCOD released corresponded to the particle size reduction, indicating a more extensive cell rupture of biosolids at higher sonication density. Considering a specific energy of $40 \mathrm{kWh} / \mathrm{kgDS}$ and an increase of the SCOD by 1.2 times at a sonication 


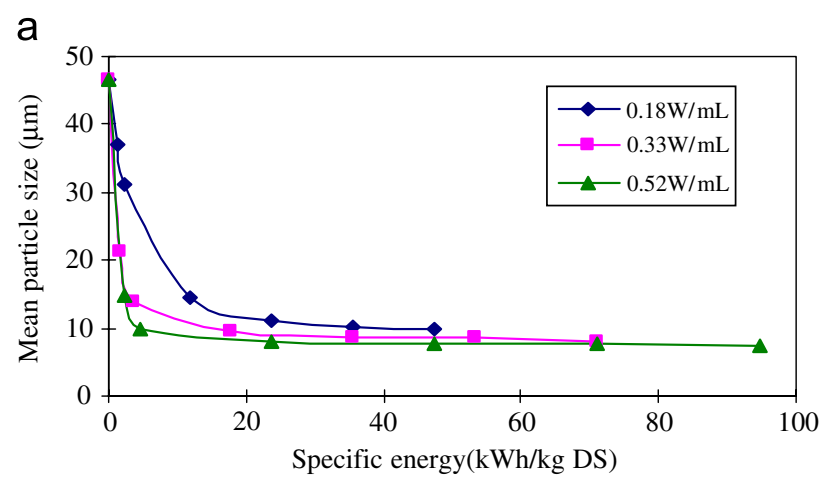

b

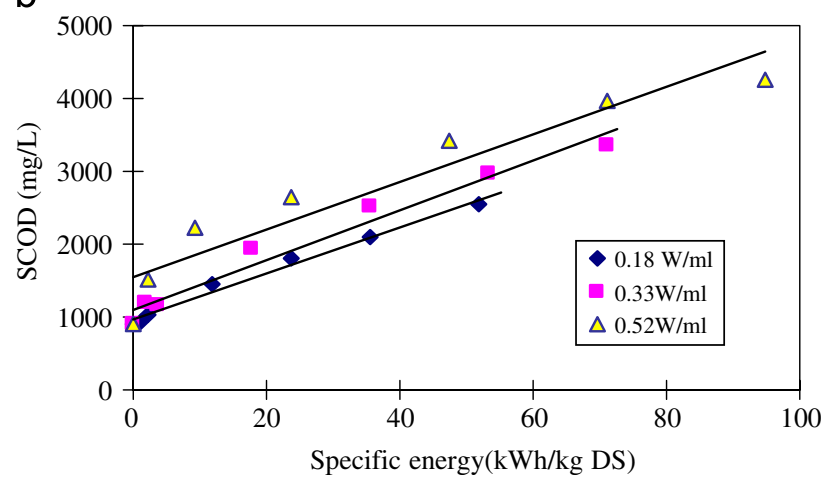

Fig. 3 - Effects of sonication density on (a) mean particle size and (b) SCOD.

density of $0.18 \mathrm{~W} / \mathrm{mL}$, higher SCOD release by 1.4 and 1.9 times at 0.33 and $0.52 \mathrm{~W} / \mathrm{mL}$, respectively, can be achieved at the same specific energy. This indicated that higher sonication density could exert stronger cavitational forces for better disruption using the same amount of energy. This suggests that sonication density is a vital operating parameter to be considered in order to achieve a cost-effective sonication, which is an essential consideration for plants to compromise energy cost and treatment efficiency.

\subsubsection{Discussion on sonication density}

It has been established that particle disruption in sludge due to sonication is attributed to the occurrence of cavitation bubbles. The fact that sonication density plays a critical role in the disruption lies in the formation and behaviour of cavitation bubbles.

Ultrasound is propagated through longitudinal waves that comprise rarefactions (negative pressures) and compressions (positive pressures). When the acoustic pressure at the rarefaction cycle is greater than the local cavitation threshold pressure, any minute cavity available will grow in size and become stable or transient bubbles (Laborde et al., 1998). It follows that the process of bubble formation could be regarded as a competition between the liquid strength $P_{\mathrm{c}}^{\mathrm{V}}$ (Eq. (5)) and acoustic pressure $P_{\mathrm{A}}$ (Eq. (6)):

$P_{c}^{v}=P_{0}-P_{v}+\frac{2}{3 \sqrt{3}} \sqrt{\frac{\left(2 \sigma_{L} / R_{0}\right)^{3}}{P_{0}-P_{v}+2 \sigma_{L} / R_{0}}}$,

$P_{\mathrm{A}}=\sqrt{2 \mathrm{I} \rho \mathrm{C}}$, where $P_{\mathrm{c}}^{\mathrm{v}}$ is the cavitation threshold pressure, $P_{\mathrm{v}}$ is the saturation vapour pressure, $R_{0}$ is the initial bubble/cavity radius, $\sigma_{\mathrm{L}}$ is the surface tension, $\mathrm{P}_{\mathrm{A}}$ is the acoustic pressure, $I$ is the ultrasound intensity, $\rho$ is the density of the medium and $C$ is the velocity of sound in that medium.

If $P_{A}$ is less than $P_{c}^{v}$, the acoustic pressure is unable to overcome the liquid strength and thus no cavitation bubble would be formed. The formation of cavitation bubbles will be realised only if $P_{A}$ is greater than $P_{c}^{v}$ (Abramov, 1998; Tatake and Pandit, 2002). It can be noted from Eqs. (5) and (6) that $P_{c}^{v}$ is dependent on the nature of the medium, while $P_{A}$ depends on both properties of the medium and ultrasound. Hence, given a similar test sample, where $P_{\mathrm{c}}^{\mathrm{v}}, \rho$ and $C$ are constant, cavitation bubble evolution will be solely dependent on sonication intensity. As expressed by Eq. (6), the acoustic pressure $P_{A}$ is proportional to the square root of sonication intensity. Correspondingly, the acoustic pressure generated in the present study (Fig. 4) increased with the sonication intensity applied. It can be deduced from such theoretical consideration that the higher the sonication intensity, the more powerful the acoustic pressure exerted to overcome liquid strength $P_{c}^{v}$, which leads to more extensive particle disruption.

Besides bubble formation, the behaviour of cavitation bubbles in the form of stable or transient bubbles is also related to sonication density. As discussed earlier, the formation of cavitation bubbles relies on the acoustic pressure which is dependent on sonication intensity, and that a higher acoustic pressure is associated with a larger number of transient bubbles. Considering the fact that transient bubbles are more vigorous than stable bubbles and the formation and collapse of transient bubble can be accomplished rapidly within a few microseconds, the disruptive effect of transient bubbles within a shorter sonication time is more prevalent than that of stable bubbles in a longer sonication time. Sonication density may thus be viewed as a prevailing parameter than sonication time with respect to bubble behaviour. The finding and hypothetical account put forward are in agreement with the results reported by Grönroos et al. (2005). It follows that the sonication process can be optimised by enhancing the sonication intensity for a stronger disruption capability within the shortest possible sonication time to minimise energy use.

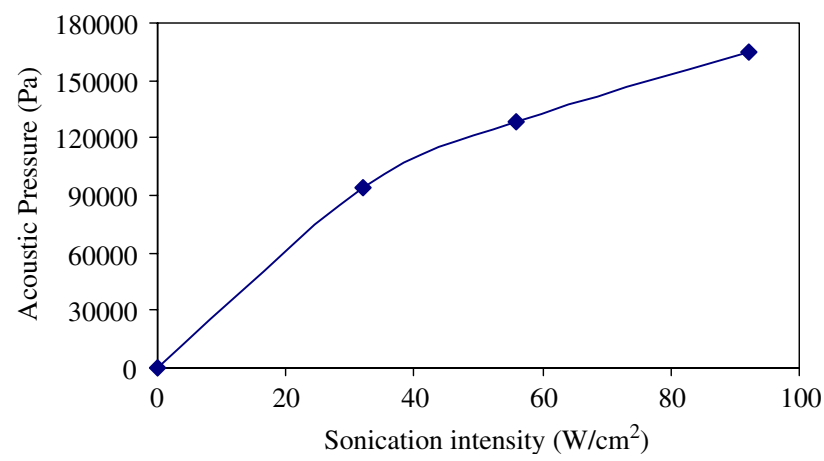

Fig. 4 - Acoustic pressure as a function of sonication intensity. 


\subsection{Sludge characteristics}

Besides the sonication parameters discussed above, the efficiency of sonication is also influenced by the sludge characteristics in terms of type of sludge and solids content. To examine the influence of these factors, a series of experiments was conducted.

\subsubsection{Type of sludge}

Primary and secondary sludge are the residues produced in the process of wastewater treatment. In most treatment plants, these sludges are often characterised by different natures and properties, owing to the different treatment processes that generate the solids. In addition to the primary and secondary sludges, mixed sludges derived from mixing the primary and secondary sludge at different ratios were also examined. Fig. 5 illustrates the effect of sonication treatment on primary sludge, secondary sludge and mixed primary-secondary sludges, with mixing ratios of 75:25, 50:50 and 25:75 by volume. The results indicated that secondary sludge exhibited the most prevalent sludge disruption in terms of particle size reduction and increase in SCOD. Clearly, particles in the secondary sludge were disrupted more readily by sonication than those of the primary sludge and mixed sludges. The sonication outcome could be explained by the fact that the cavitational strength of a sludge liquid is determined by its physicochemical properties and is primarily dominated by the weak spots it contains (Abramov, 1998).

a

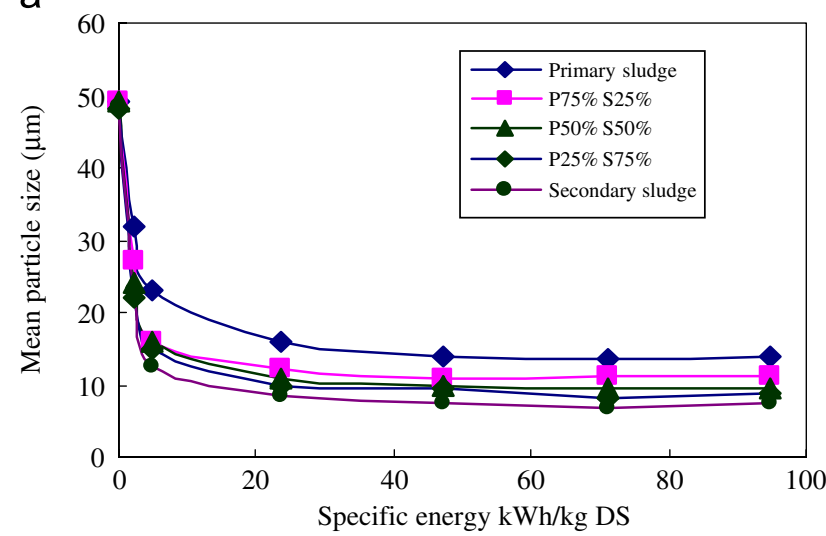

b

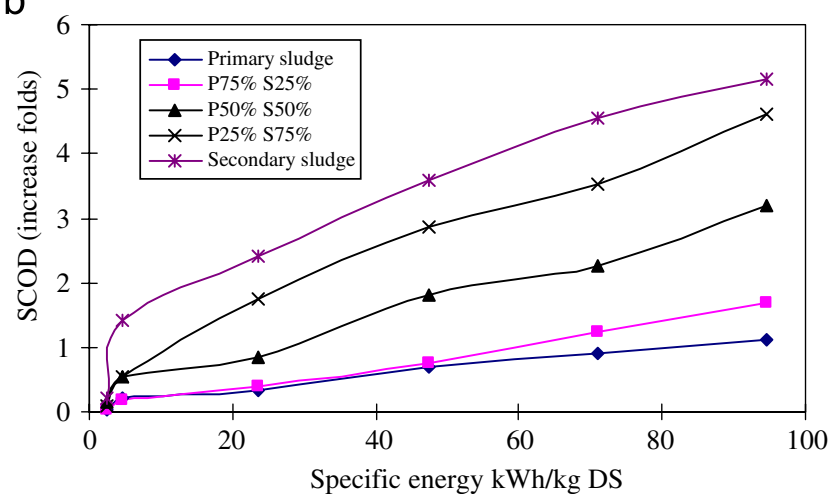

Fig. 5 - Effects of sludge type on (a) mean particle size and (b) SCOD (sonication density was fixed at $0.52 \mathrm{~W} / \mathrm{mL}$ ).
Table 2 - Properties of untreated sludge

\begin{tabular}{lcc}
\hline Properties & $\begin{array}{c}\text { Primary } \\
\text { sludge }\end{array}$ & $\begin{array}{c}\text { Secondary } \\
\text { sludge }\end{array}$ \\
\hline SCOD (mg/L) & $1000-1500$ & $500-700$ \\
TCOD (mg/L) & $14,000-17,500$ & $12,500-18,000$ \\
SCOD/TCOD & $0.05-0.09$ & $0.03-0.06$ \\
pH & $6.1-6.5$ & $6.2-6.6$ \\
TS $(\%)$ & $0.9-3.9$ & $0.8-3.9$ \\
VS/TS (\%) & $76.4-78.6$ & $77.3-82.6$ \\
Mean particle size & $47.2-53.4$ & $45.6-50.4$ \\
$(\mu \mathrm{m})$ & & \\
\hline
\end{tabular}

In the present study, the primary sludge consisted mainly of non-degradable substances such as plastics, textile, sand and bones that were not easily disrupted, while the secondary sludge was composed mainly of biological solids that were derived from the activated sludge process, which is more readily disrupted on sonication (Table 2 ).

Based on the theoretical consideration that cavitation bubble formation can be viewed as a competition between liquid strength and acoustic pressure as discussed previously, the disruption in this case could be regarded as a competition between sonication density and the structural strength of sludge particles. There is likely a critical sonication density level, beyond which the particle binding force would be overcome and be broken up. If the mechanical forces induced by sonication exceed this critical level, disruption of particles would take place.

From Eqs. (5) and (6), both $P_{\mathrm{c}}^{\mathrm{v}}$ and $P_{\mathrm{A}}$ depend on the nature of the medium. The cavitation threshold for sludge of different properties is unlikely to be consistent since variation in sludge properties such as solids content could affect $P_{c}^{v}$. This might explain the inconsistent sludge thresholds reported in different studies: $0.1 \mathrm{~W} / \mathrm{cm}^{2}$ by Tiehm et al. (2001), $0.22 \mathrm{~W} / \mathrm{mL}$ by Chu et al. (2001), $20 \mathrm{~kJ} / \mathrm{L}$ by Bougrier et al. (2005) and $30 \mathrm{~kJ} / \mathrm{L}$ by Gonze et al. (2003). The minimum ultrasound level of $0.18 \mathrm{~W} / \mathrm{mL}\left(32 \mathrm{~W} / \mathrm{cm}^{2}\right)$ used in the present study appeared to have exceeded the threshold evidenced by particle size reduction by as much as $35 \%$. As sewage sludge is often of a heterogeneous nature comprising various compounds (Gonze et al., 2003), there exists a range of liquid strength levels, therefore resulting in varying levels of thresholds for sonication. It is hence suggested that the critical sonication density be determined specifically based on the properties of the sludge to be sonicated.

\subsection{Solid content}

Fig. 6(a) depicts the change of mean particle size in the secondary sludge with different solids contents sonicated at a density of $0.52 \mathrm{~W} / \mathrm{mL}$. Significant particle disruption was noted in sludge samples with TS contents below $2.9 \%$, while the sample with the highest TS content of $3.8 \%$ exhibited marginal particle size reduction. The influence of solids content on disruption is also reflected from the release of inter-cellular substances measured as SCOD. As shown in 

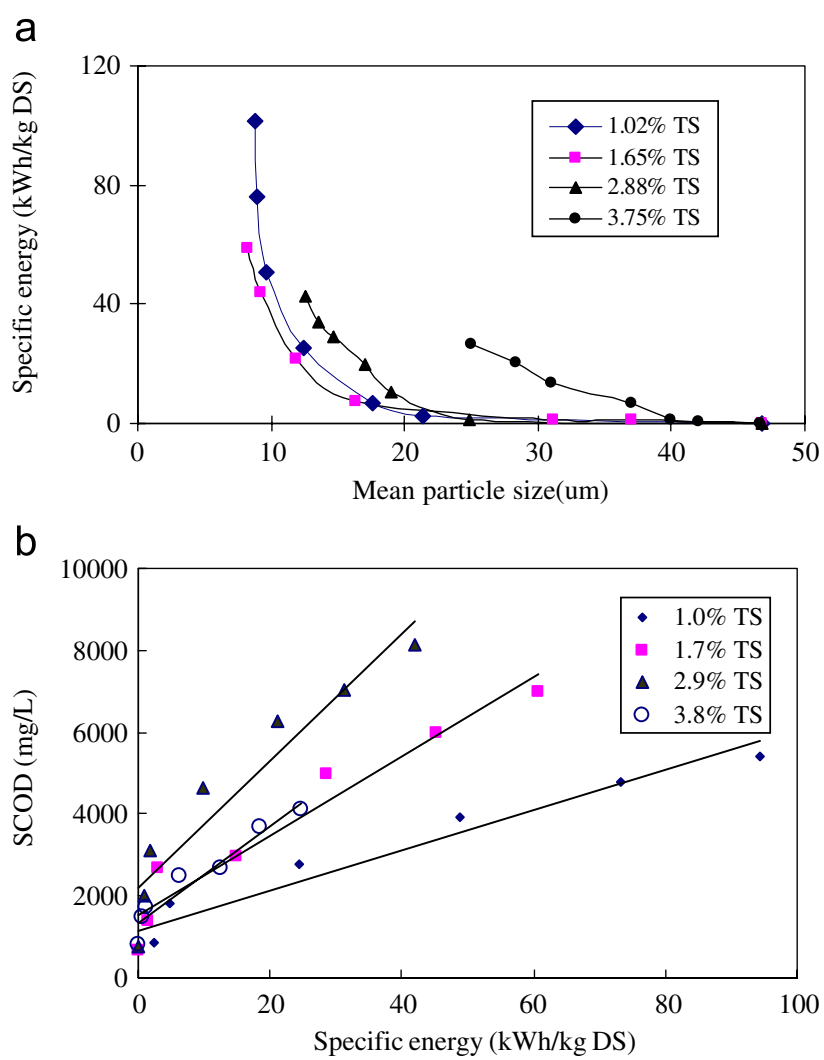

Fig. 6 - Effects of solids concentration on (a) mean particle size and (b) SCOD (sonication density was fixed at $0.52 \mathrm{~W} / \mathrm{mL}$ ).

Fig. 6(b), a higher increase in SCOD was accomplished within the range of solids content of $1.0-2.9 \%$ TS at the same specific energy. When the solids content increased to $3.8 \% \mathrm{TS}$, the increase in SCOD was inferior to those of lower solids content. It appears that there exists an optimal range of solids content for effective disruption by sonication. Neis et al. (2000) reported that the efficiency of sludge disruption by sonication increased with solids content. The study, however, did not explore the limit of solids content.

Sonication efficiency depends on a number of parameters, and analysis of their interactions can be a complicated task. To simplify the complexity and to investigate the optimal range of solids content, this study proposed a definition of ultrasound disruption index $D$, which reflects a relationship between the disruption efficiency and the solids content following

$\mathrm{D}=\gamma(\mathrm{S} / \mathrm{E})$,

where $S(\mathrm{mg} / \mathrm{L})$ is the SCOD in sludge released by disrupted cells after sonication, E (kWh/kg DS) is the specific energy consumption to sonicate $1 \mathrm{~kg}$ dry solids of sludge, $\mathrm{S} / \mathrm{E}$ is the slope of the trend line for SCOD versus specific energy obtained from Fig. $6(\mathrm{~b})$ and $\gamma$ is a correlation constant relative to the sonication density (in a series of experiments of concentration effects, the density remained $0.52 \mathrm{~W} / \mathrm{mL}$; hence $\gamma$ is regarded as 1 ).

Fig. 7 illustrates the relationship between solids content and index $D$ for sonication of primary and secondary sludges. From the relationship established, it can be deduced that the

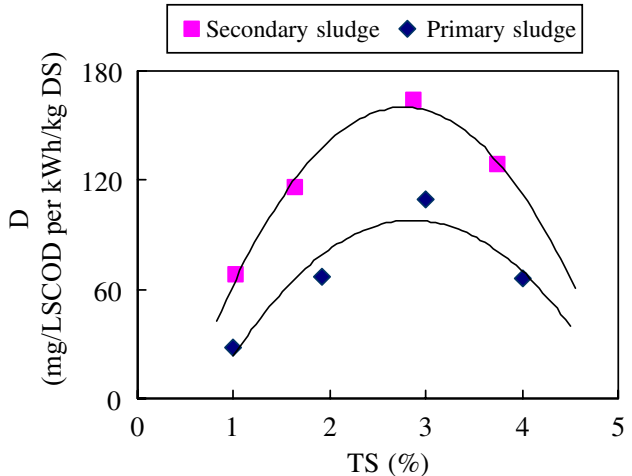

Fig. 7 - Optimal solids concentration range for sonication treatment (sonication density was fixed at $0.52 \mathrm{~W} / \mathrm{mL}$ ).

optimal range of solids content for sonication lies in a range between $2.3 \%$ and $3.2 \%$ TS. In other words, the highest SCOD increase per unit specific energy representing the most efficient ultrasound disruption can be derived for sludge within the optimal TS range. It should be noted that index D is influenced by the type of sludge; hence the index should be established experimentally for a specific type of sludge.

\subsubsection{Discussion on solids content}

The impact of cavitation bubbles is dictated by the properties of sludge and ultrasound. Since propagation of ultrasound waves in a medium is accompanied by unavoidable energy loss through attenuation, adsorption and dissipation (Abramov, 1998), the behaviour of ultrasound dissipation would depend on the nature and extent of medium homogeneity. Generally, equal portions of acoustic energy are adsorbed over a given path interval as (Abramov, 1998): shown below

$I_{x}=I_{0} \mathrm{e}^{-2 \alpha x}$,

where $I_{0}$ is the sound intensity at the source, $I_{x}$ is intensity at the distance $x$ from the source, $\alpha$ is the coefficient of absorption and $x$ is the distance covered by the water.

It had been established that the absorption coefficient would increase with liquid viscosity (Abramov, 1998). Set on a basis that the viscosity of sludge increases with its solids concentration a thickened sludge would pose a greater energy adsorption and dissipation. On the other hand, it is also possible that sludge of excessive solids content might hamper and reduce the ultrasound intensity in areas remote to the transducer probe. At lower sonication intensity, cavitation bubbles, especially the transient bubbles, may not develop in those remote areas in the medium.

In a liquid-solid system such as those existing in sludge, sufficient quantity of liquid is necessary for vaporisation to take place and to form micro-bubbles during cavitation. If the solids concentration is too high, liquid vaporisation may be hampered, thereby affecting cavitation bubble formation. Moreover, the cavitation bubbles if so generated may not be able to propagate due to a lack of liquid channels and intensive bubble collapse around the probe, resulting in localised high temperature and pressure. This could lead to operational failure, probe erosion and machine life-span deterioration. Although the solids content of sludge is, in 
most cases, beyond the control of plant operators, it is still desirable to establish limiting solids contents for monitoring purposes. With a good monitoring system in place, operation interruption due to sludge overloading can be avoided, and the costly sonication system can also be protected.

\section{Conclusions}

The role of sonication time, sonication density, type of sludge and solids content in ultrasound sonication was examined. It can be concluded from the experimental results and theoretical considerations that the most superior effects of ultrasound disruption were associated with the secondary sludge at higher sonication density $(0.52 \mathrm{~W} / \mathrm{mL})$ and shorter sonication time (1 $\mathrm{min})$, within an optimum total solids (TS) content ranging between $2.3 \%$ and $3.2 \%$. Particle disruption was most profound in the initial period of sonication due to the explosive cavitational effect caused by transient bubbles. Sonication density plays a critical role in cavitation bubble formation and bubble behaviour. Sonication process can be optimised by enhancing the ultrasonic density for generation of more vigorous transient bubbles, while keeping the sonication time short to save energy. Sonication exhibited better particle disruption on secondary sludge than primary sludge and mixed sludges. This provides a valuable rating with respect to the type of sludge subject to sonication for an efficient operation. The optimal range of solids content has been established for a cost-effective sonication. Within the optimal solids content, efficient sonication can be realised. The knowledge derived from the influence of solids content on sonication would provide useful guidelines on sonication system installation, equipment protection and process reliability.

\section{R E F E R E N C E S}

Abramov, O.V., 1998. High-Intensity Ultrasonics: Theory and Industrial Applications. Golden and Breach Science Publishers, Amesterdam, Netherlands, pp. 80-82.

APHA, 1998. Standard methods for the examination of water and wastewater: including bottom sediments and sludges. In: Clesceri, L.S., Greenberg, A.E., Eaton, A.D., Franson, M.A.H. (Eds.). American Public Health Association, American Water Works Association, Water Environment Federation, USA.

Bougrier, C., Carrere, H., Delgenes, J.P., 2005. Solubilisation of waste-activated sludge by ultrasonic treatment. Chem. Eng. J. 106 (2), 163-169.
Chiu, Y., Chang, C., Lin, J., Huang, S., 1997. Alkaline and ultrasonic pretreatment of sludge before anaerobic digestion. Water Sci. Technol. 36, 155-162.

Chu, C.P., Chang, B.-V., Liao, G.S., Jean, D.S., Lee, D.J., 2001. Observations on changes in ultrasonically treated wasteactivated sludge. Water Res. 35 (4), 1038-1046.

Eastman, J.A., Ferguson, J.F., 1981. Solubilization of particulate organic carbon during the acid phase of anaerobic digestion. J. WPCF 53, 352-366.

Grönroos, A., Kyllonen, H., Korpijarvi, K., Pirkonen, P., Paavola, T., Jokela, J., Rintala, J., 2005. Ultrasound assisted method to increase soluble chemical oxygen demand (SCOD) of sewage sludge for digestion. Ultrason. Sonochem. 12 (1-2 SPEC ISS), 115-120.

Gonze, E., Pillot, S., Valette, E., Gonthier, Y., Bernis, A., 2003. Ultrasonic treatment of an aerobic activated sludge in a batch reactor. Chem. Eng. Process. 42 (12), 965-975.

Harrison, S.T.L., 1991. Bacterial cell disruption: a key unit operation in the recovery of intracellular products. Biotechnol. Adv. 9 (2), 217-240.

Jorand, F., Zartarian, F., Thomas, F., Block, J.C., Bottero, J.Y., Villemin, G., Urbain, V., Manem, J., 1995. Chemical and structural (2D) linkage between bacteria within activated sludge flocs. Water Res. 29, 1639-1647.

Laborde, J.-L., Bouyer, C., Caltagirone, J.-P., Gerard, A., 1998. Acoustic bubble cavitation at low frequencies. Ultrasonics 36 (1-5), 589-594.

Mao, T., Hong, S.Y., Show, K.Y., Tay, J.H., Lee, D.J., 2004. A comparison of ultrasound treatment on primary and secondary sludges. Water Sci. Technol. 50 (9), 91-97.

Mao, T., Show, K.Y., 2007. Influence of ultrasonication on anaerobic bioconversion of sludge. Water Environ. Res. 79 (4), 436-441.

Neis, U., Nickel, K., Tiehm, A., 2000. Enhancement of anaerobic sludge digestion by ultrasonic disintegration. Water Sci. Technol. 42 (9), 73-80.

Onyeche, T.I., Schläfer, O., Bormann, H., Schröder, C., Sievers, M., 2002. Ultrasonic cell disruption of stabilized sludge with subsequent anaerobic digestion. Ultrasonics 40, 31-35.

Tatake, P.A., Pandit, A.B., 2002. Modelling and experimental investigation into cavity dynamics and cavitational yield: Influence of dual frequency ultrasound sources. Chem. Eng. Sci. 57 (22-23), 4987-4995.

Tiehm, A., Nickel, K., Neis, U., 1997. The use of ultrasound to accelerate the anaerobic digestion of sewage sludge. Water Sci. Technol. 36, 121-128.

Tiehm, A., Nickel, K., Zellhorn, M., Neis, U., 2001. Ultrasonic waste activated sludge disintegration for improving anaerobic stabilization. Water Res. 35 (8), 2003-2009.

Weemaes, M., Grootaerd, H., Simoens, F., Verstraete, W., 2000. Anaerobic digestion of ozonized biosolids. Water Res. 34 (8), 2330-2336.

Young, G.C., 1980. Performance of anaerobic filters under transient loading and operating conditions. In: Proceedings of the Seminar/Workshop on Anaerobic Filters: An Energy Plus for Wastewater Treatment, Orlando, FL, January, pp. 159-170. 